\title{
Does Maternal Age Affect Children's Test Scores?*
}

\author{
Andrew Leigh \\ Economics Program \\ Research School of Social Sciences \\ Australian National University \\ andrew.leigh@anu.edu.au \\ http://econrsss.anu.edu.au/ aleigh/ \\ Xiaodong Gong \\ Australian Treasury \\ xiaodong.gong@treasury.gov.au
}

\begin{abstract}
We estimate the relationship between maternal age and child outcomes, using indices aimed at measuring overall outcomes, learning outcomes, and social outcomes. In all cases, we find evidence that children of older mothers have higher outcomes. Not only do children born to mothers in their twenties do better than children born to teen mothers, but children born to mothers in their thirties do better than children born to mothers in their twenties. However, when we control for other socioeconomic characteristics, such as family income, parental education, and single parenthood, the coefficients on maternal age become small and statistically insignificant. The only exception is an index of social outcomes, which is positively associated with maternal age, even controlling for socioeconomic factors. For cognitive outcomes, young motherhood appears to be a marker, not a cause, of poor child outcomes.
\end{abstract}

Keywords: cognitive development, non-cognitive skills, intergenerational human capital transmission

JEL Codes: I2, J13

\footnotetext{
* This paper uses unit record data from the Longitudinal Study of Australian Children (LSAC) Survey. The LSAC Project was initiated and is funded by the Australian Government Department of Families, Housing, Community Services and Indigenous Affairs (FaHCSIA) and is managed by the Australian Institute of Family Studies (AIFS). The findings and views reported in this paper, however, are those of the authors and should not be attributed to either FaHCSIA or AIFS. We are grateful to Mark Wooden, two anonymous referees, and FaHCSIA staff for valuable comments and suggestions on earlier drafts. Susanne Schmidt and Elena Varganova provided outstanding research assistance.
} 


\section{Introduction}

Most studies of early childbearing have focused on the consequences for the mother in terms of employment, human capital accumulation, and earnings. However, it is possible that a mother's age also has a causal effect on her child's outcomes. Further, while most studies have concentrated on teenage motherhood, policymakers might also be concerned with the relationship for older mothers. Put simply, we might want to know not only whether children of 28 year-old mothers do better than children of 18 year-old mothers, but also whether children of 38 year-old mothers do better than children of 28 year-old mothers.

While most government policies ignore maternal age in a statutory sense, they may have a differential effect in an economic sense. For example, a Maternity Payment ('Baby Bonus') of \$5,000 is likely to have a larger impact on the behaviour of an 18 year-old mother than of a 38 year-old mother, due to the different hourly wages and wealth levels of the two individuals. Conversely, higher levels of government assistance for in vitro fertilisation treatments (IVF) are likely to increase the share of older mothers. Better understanding the development of children born to mothers of different ages is therefore relevant to shaping government policy even in an environment where maternal age is rarely an explicit condition of benefit receipt.

In theory, there are various channels through which maternal age might affect children's outcomes. Theories suggesting that maternal age will be positively 
correlated with child outcomes include the possibility that younger mothers may be emotionally unprepared for motherhood, that they may have less parenting skills than if they had become parents at an older age, that they may be less sensitive in responding to their infants, or that they may make more poorly informed choices about daycare, preschool and kindergarten. Conversely, it might be the case that maternal age will be negatively correlated with child outcomes - for example if older mothers are less physically fit, have less support from grandparents, or spend less time with their children because their opportunity cost (market wage) is higher.

In this paper, we estimate the relationship between the age of a child's mother and the outcome indices for their children in early years (ages 4-5). We use data from Australia, which has seen a steady shift towards women having children at an older age. Each year, the age of the typical mother rises by approximately two months. Yet there has been little evidence on whether this substantial social change might have a positive or negative impact on children.

A major empirical challenge in estimating the causal effect of maternal age on children's outcomes is that any observed correlation will not necessarily imply causality. For example, women who have babies at a young age may also be poorer, less educated, and less likely to be married than older mothers. Younger mothers may also be different with respect to unobservable characteristics, such as intrinsic motivation, academic aptitude and social networks. If the kinds of women who have 
children at a young age are systematically different from the kinds of women who have children at older ages, then we cannot assume that differences in the outcomes of children of younger mothers and older mothers tell us what would happen if the same woman chose to delay childbearing. To a modest extent, we can address some of these difficulties by carrying out a multiple regression in which we hold constant observable factors such as family income, whether there are two parents present, and the presence of siblings.

To preview our findings, we observe a positive and statistically significant relationship between maternal age and children's outcomes. This relationship exists not only when comparing teenage mothers with mothers in their twenties, but also across other ages. However, the relationship is quite sensitive to the addition of other controls, suggesting that mother's age may be a proxy for other indices of disadvantage. For the overall index and learning index (though not for the social index), mother's age has no significant association with child outcomes once socioeconomic controls are added to the regression.

The remainder of this paper is structured as follows. In Section 2, we provide some background to our study by presenting an overview of trends in maternal age over recent decades, and reviewing the literature on the relationship between maternal age and child outcomes. In Section 3, we discuss the data from which our results are drawn: the Longitudinal Survey of Australian Children (LSAC). In Section 4, we 
present results, showing the relationship between maternal age and the overall, learning and social indices. The final section concludes.

\section{Background}

\section{(a) Trends in Maternal Age}

Over the past two decades, there has been a steady increase in the median age at which Australian women have their first child, and subsequent children. Figure 1 charts the median age of all confinements (that is, pregnancies that resulted in at least one live birth) and first nuptial confinements, using data up to 2004 from the ABS Births series. Over the period 1984-2004, the median age at first nuptial confinement increased by about $4 \frac{1}{2}$ years, while the median age of all confinements increased by about $3 \frac{1}{2}$ years. ${ }^{1}$ The trend is approximately linear. Over the period $1984-2004$, the median age of new mothers rose by about 2 months per year, while the median age at which married mothers had their first child rose by about 3 months per year.

\section{<Figure 1>}

To see these patterns in more detail, Figure 2 charts age-specific fertility rates by 5-year bands, for selected years between 1924 and 2004. Comparing 1984 and 2004, it can be seen that while the number of teenage mothers has fallen slightly, the largest

1 The ABS does not provide data on the median age at first birth, only on the median age at the time of first nuptial confinement (available from 1975 onwards). The ABS caution that a first nuptial confinement "is the first confinement in the current marriage and therefore does not necessarily represent the woman's first ever confinement resulting in a live birth" (ABS, 2005, p.82). 
changes are among women aged 20-24 (whose fertility rates have nearly halved), and women aged 35-39 (whose fertility rates have more than doubled). The most significant changes in childbearing over recent decades is the shift from women having children in their twenties to women having children in their thirties.

\section{<Figure 2>}

\section{(b) Previous Literature}

Most of the literature on maternal age and children's educational performance has used data from the United States. ${ }^{2}$ The initial wave of studies in this literature tended to find that children of young or teenage mothers have lower test scores, lower educational attainment, and more behavioural problems than children born to older mothers. In general, these studies found effects that were both statistically significant, and of a substantial magnitude.

For example, using test scores when children were aged 15-17, Card (1981) reported that the cognitive gap between those born to teenage parents and those born to older parents was 0.4 standard deviations. Similarly, Dubow and Luster (1990) reported that the children born to teenage mothers scored one standard deviation below their classmates on vocabulary tests. Moore and Snyder (1991) found a positive

\footnotetext{
${ }^{2}$ We focus in this section on the literature relating specifically to maternal age and child outcomes, and do not discuss papers that look at the effect of early childbearing on the mother herself. In the Australian context, an excellent example of this type of study is Bradbury (2006).
} 
relationship between children's cognitive skills and their mother's age at birth. For white children, the relationship between maternal age and child test scores became small and statistically insignificant once the researchers controlled for parental test scores and socioeconomic variables, but for minority children it was robust to adding these controls. (For studies in a similar vein, see for example Baldwin \& Cain, 1980; Furstenberg et al., 1987; Fergusson \& Lynskey, 1993; Moore et al., 1997; Levine. 2001; Fergusson \& Woodward, 1999.)

However, not all studies have found a positive association between a mother's age and her child's outcomes. Using US data from the 1979 National Longitudinal Survey of Youth, Geronimus et al. (1994) found no significant difference in the test scores of US children with teenage mothers and non-teenage mothers. ${ }^{3}$ A similar analysis by Turley (2003) used additional waves of the same survey, and coded mother's age as a continuous variable. The study concluded that once sister-pair fixed effects were added to the regression, there was no significant relationship between maternal age and mathematics or vocabulary scores (though the coefficient on maternal age was still positive and significant when the dependent variable was reading scores).

A potentially confounding factor affecting the relationship between child outcomes

${ }^{3}$ Other studies have used a similar approach to look at the effect of maternal age on children's socioeconomic outcomes, such as income. For example, using data from three US surveys (the 1979 National Longitudinal Survey of Youth, the 1968 National Longitudinal Survey of Labor Market Experience, and the Panel Study of Income Dynamics), Geronimus and Korenman (1992) found that in the two NLS datasets though not the PSID - most of the coefficients from the sister-pair fixed effects specifications are smaller than in the cross-section. 
and maternal age is maternal education. Using data from Wisconsin, Barratt (1991) noted that the correlation between a mother's age at child birth and the child's score on the Peabody Picture Vocabulary Test was 0.09 , much lower than the correlation between a mother's education and the child's score, which was 0.19 . Using data from Florida, Hollander (2001) found that controlling for maternal education, marital status, poverty, and race eliminated the positive association between educational achievement and maternal age. Indeed, controlling for parental background, children born to mothers aged over 35 were more likely to be placed in classes for children with mild mental handicaps (this is the only study we know of that finds a negative relationship between maternal age and child educational outcomes).

\section{The Longitudinal Survey of Australian Children}

Data used for this analysis are drawn from Wave 1 of the LSAC survey conducted in 2004. The survey gathers comprehensive, national Australian data on all the important domains of a child's life — their experiences within their families and communities, their health, their child care experiences, and the early years of their education — for two cohorts of about 5,000 children each, who were aged 0-1 and 4-5 in 2004. Here, we use the sample of children aged 4-5 in 2004.

The variables in LSAC are created from direct measurements or tests of children, or from questioning the parents. From these variables the continuous, standardised 
LSAC Outcome Indices are created by the survey team as composite measures to describe children's development. To be specific, three indices on physical, social and emotional, and learning domains were created, plus an overall index, which is the mean of the three indices. These indices were standardised to a mean of 100 and a standard deviation of 10 . Since our focus is on cognitive and social skills, we do not analyse differences in the physical domain, though it does come into our analysis via the overall index (of which the physical domain comprises one-third). Together with these indices, indicators for the bottom (problematic) 15 per cent children in each area are also generated. These indices are described in more detail in Appendix 1. For more details, see Sanson et al. (2005). We create an additional indicator which equals one if the studied child is in a problematic area in any of the three domains, and zero otherwise.

In this paper, we focus on the development of the 4-5 year-olds, for whom we have detailed development indicators. In total, there are 4,983 children in the sample. We first dropped 8 children who do not have a parent in the household (where parent includes biological, adopted, step and foster parents). We then dropped 875 observations in which household income is missing, 2 observations in which Indigenous status is missing, 64 observations in which birth weight is missing, 5 observations in which father's education is missing, 6 observations where LSAC indices are missing, and 27 observations where mother's age is missing. Comparisons of the socioeconomic variables in the full sample and sub-sample do not indicate any 
substantial sample selection problems (see Appendix 2).

Our final sample consists of 3,996 observations. Table 1 shows summary statistics for the variables reported in our tables. Importantly for our purposes, the average mother in our sample was aged 30 years and 3 months at the time of her child's birth, which is close to the median age in the general population in 2000 (29.8 years). Figure 3 shows a histogram of the ages of mothers in our sample, and of mothers in the general population who gave birth in 2000 .

$<$ Figure 3>

51 per cent of the studied children are boys and 83 per cent are 4 year-olds (the remainder are 5 year-olds). The average family income is $\$ 1,310$ per week. The summary statistics for variables not reported in Table 1 also suggest that the sample is reasonably representative of Australian families with young children. For example, 88 per cent of children have siblings in the household and 48 per cent of them have younger siblings in the household. 3 per cent of the children are Indigenous and 90 per cent of the children speak English at home. 15 per cent of the children are from single-parent families. Around 28 per cent of mothers and 24 per cent of fathers have a university qualification. The average age of fathers in our sample was 33 years and 1 month (about 3 years older than mothers in the sample).

\section{<Table 1>}

The continuous outcome indices and discrete problem and positive indicators are also 
summarised in the table. Due to the deletion of observations, the averages of these indices are slightly different from 100 (continuous indices) and 15 per cent mark (discrete indicators). 32 per cent of the children are below the lower cut-off point in at least one domain.

\section{Maternal Age and Child Outcomes}

In this section, we estimate several models, following a common pattern. The first model (shown in column 1 of Tables 2-7) estimates the relationship between the outcome index and a quadratic in mother's age, controlling only for the age and sex of the child. (A quadratic is used to allow for the possibility that the effect of maternal age on child outcomes is non-linear.) We regard this first model as the uncontrolled relationship between maternal age and children's outcomes. In the second model (shown in column 2 of Tables 2-7), we include a control for family income. In the third model (shown in column 3 of Tables 2-7), we include a set of socioeconomic controls that may be correlated with both maternal age and child outcomes: language spoken at home, Indigenous status, having both parents present, parental education, presence of siblings, whether siblings are older or younger, indicator variables for each state and territory, an indicator for living in a metropolitan area, an indicator for living in a remote area, and a composite index of the socioeconomic status of the neighbourhood. ${ }^{4}$ In the fourth model (shown in column 4 of Tables 2-7), we add a

\footnotetext{
${ }^{4}$ Specifically, our measure of neighbourhood socioeconomic status is the Australian Bureau of Statistics' SEIFA Advantage/Disadvantage Index, based on the 2001
} 
control for child's birth weight.

In each case, we focus on maternal age rather than paternal age, since this has been the main variable of interest in the literature. Not surprisingly, however, the ages of a child's mother and father are highly correlated $(\rho=0.66)$. Since we do not control for paternal age, our results should therefore be regarded as indicative of the effects of having older parents, not merely an older mother. ${ }^{5}$ While our regressions include a detailed set of socioeconomic indicators, we deliberately do not include behavioural controls. We regard measures of the parental environment (for example parenting style, time spent with children, smoking, excessive risk-taking), as potential channels through which maternal age might affect child outcomes. As such, we do not include these controls in our regressions.

Our regressions take the following form. Let $y_{i}$ be the continuous index (overall, learning domain, or social domain), and $d_{i}$ be the discrete problem indicators, then the linear model and probit are specified as follows, respectively:

\footnotetext{
Census.

${ }^{5}$ An important point made in the recent literature on maternal age and test scores is that one should not necessarily assume that maternal age is exogenous. Similarly, one should not assume that the gap between parents' ages is exogenous. For example, a recent paper in the medical literature has found that when controlling for the other parent's age, maternal age is positively related to test scores, while paternal age is negatively related to test scores (Saha et al., 2009). However, if the age gap between partners is correlated with unobservables (such as emotional intelligence or the quality of time spent with children), then this approach will produce a biased estimate of the causal impact of maternal age on children's outcomes.
} 


$$
\begin{aligned}
& y_{i}=\alpha+x_{i}{ }^{\prime} \beta+\varepsilon_{i} \\
& \operatorname{Pr}\left(d_{i}=1\right)=\Phi\left(\eta+x_{i}{ }^{\prime} \gamma\right)
\end{aligned}
$$

Where $x_{i}^{\prime}$ is the vector of explanatory variables, $\alpha, \beta, \gamma$, and $\eta$ are parameters, $\varepsilon_{i}$ is the error term in the linear model, and $\Phi$ is the cumulative normal function. The coefficients in (1) give out the marginal effect of the corresponding variables on index $y_{i}$, other things equal. The coefficients in (2) are presented as marginal effects (rather than probit coefficients) in the tables.

Tables 2, 3 and 4 show the results using the continuous indices. In the first columns of each of these tables, we find that - controlling for the child's age and sex - children of mothers who are one year older score 1.0 to 1.6 points higher on the overall index, and the marginal effect of maternal age diminishes slightly for older mothers. ${ }^{6}$ These effects are substantial. One way to put the maternal age effects into context is to compare them to the child's age coefficients. For the overall index and learning index, a 5 year-old child born to a 30 year-old mother scores at a similar level to a 4 year-old child born to a 31 year-old mother. Another approach is to compare the maternal age coefficients to the child's gender coefficients. On each of the three tests, girls score significantly better than boys. For each of the indices, a girl born to a 30 year-old mother scores at a similar level to a boy born to a 32 or 33 year-old mother.

${ }^{6}$ Combining the effects of Mother's Age and Mother's Age ${ }^{2}$, the effect of an additional year of maternal age does not become negative until the mid-forties. As Figures 2 and 3 show, very few women bear children in their mid-forties. 
However, the maternal age coefficient is highly sensitive to the addition of controls. In the second column, we control for family income (an important determinant of child outcomes, and a marker of other forms of advantage). This reduces the maternal age coefficients by one-half in the overall index specification, by two-thirds in the learning index specification, and by two-thirds in the social index specification.

In the third column, we add a fuller set of socioeconomic controls, and find that this further reduces the association between maternal age and child outcomes. For both the overall and learning indices, the coefficients on maternal age attenuate towards zero and become statistically insignificant. However, in the social index specification, the relationship between maternal age and child outcomes is robust to including socioeconomic controls. This remains true even when we control for the child's birth weight. Overall, our specifications explain between 4 and 16 per cent of the variance in children's outcome indices.

The magnitude of the maternal age coefficients in the social index specifications are both statistically and economically significant. For example, the coefficients in the fourth column of Table 4 suggest that a child of a 30 year-old mother with the same socioeconomic characteristics as a 20 year-old mother would be expected to have a social index that was 2.4 points higher (around one-quarter of a standard deviation). ${ }^{7}$

7 Together, the coefficients on Mother's Age and Mother's Age ${ }^{2}$ in column 4 of Table 4 imply that the social index continues to increase with maternal age until the point at 
This difference is more than twice the marginal effect of doubling family income (holding the other socioeconomic measures constant). However, it remains possible that in this specification the maternal age coefficient is still picking up the impact of other unobserved family characteristics. Since our data do not provide exogenous variation in maternal age (and do not permit us to estimate a model with sister-pair fixed effects), the result on the social index should be viewed with some caution.

$<$ Table 2>

$<$ Table 3>

$<$ Table 4>

Tables 5, 6 and 7 show results from a probit specification, in which the dependent variable is an indicator for whether the child is below the lower cut-off for particular indices. In Table 5, the dependent variable is equal to 1 if the child is below the lower cut-off for any of the three indices (physical, learning or social). In Tables 6 and 7, the dependent variable denotes being below the lower cut-off for the learning index and social index, respectively.

In each of these specifications, we find that the relationship between maternal age and child outcomes is not robust to the inclusion of additional controls. When controlling only for child age and sex (column 1), children with older mothers are less likely to be in a problematic area. But with the addition of family income, the coefficients on maternal age become small and statistically insignificant. Adding controls for socioeconomic status and birth weight further attenuates the coefficients. In sum, we

which the mother is aged 38 . 
find no robust evidence of a causal link between maternal age and the chance that a child will be in a problematic area for the key indices.

$<$ Table 5>

$<$ Table 6>

<Table 7>

Until this point, we have imposed a specific functional form on the relationship between maternal age and child outcomes. In the above tables, we include a quadratic in maternal age, which is more flexible than the linear specification used in most of the literature, but which is still unlikely to be a perfect fit to the data.

To explore the non-parametric relationship between children's overall outcome indices and maternal age, we therefore estimate a regression akin to that presented in the first column of Table 2, but with dummy variables for mother's age used in place of the quadratic in mother's age. ${ }^{8}$ The excluded group is teenage mothers, so all coefficients show the relationship between maternal age and the outcome index, relative to teen mothers.

Figure 4 plots the maternal age coefficients from this regression, along with their associated 95 per cent confidence intervals. Since the standard deviation of the overall outcome index is about 10 , these results suggest that, relative to teen mothers, the

${ }^{8}$ Specifically, this takes the form $y_{i}=\alpha+\sum_{j=20}^{44}\left(I_{j i} \delta_{j}\right)+\varepsilon_{i}$ where $I_{j}$ is an indicator variable for the mother's age (ranging from 20 to 44), $\alpha$ and $\delta$ are parameters, and $\varepsilon_{i}$ is the error term in the linear model. 
outcome index is 0.2 standard deviations higher (though not statistically significant) for mothers in their early twenties, 0.5 standard deviations higher for mothers in their mid-twenties, and 0.6 standard deviations higher for mothers in their thirties. We find no evidence that the association between maternal age and the outcome index becomes negative at older ages, though the standard errors are quite large for women aged over 40 .

\section{$<$ Figure 4>}

To create Figure 5, we estimate a similar regression, but this time including controls for socioeconomic status (analogous to the third column of Table 2, but with maternal age dummies in place of the maternal age quadratic). ${ }^{9}$ Although the point estimates on the coefficients range from 0 to 3 , almost none of the coefficients are statistically significant (that is, the bottom 95 per cent confidence band generally lies below zero). This underscores the results in Table 2: even allowing maternal age to take a flexible functional form, mother's age has no statistically significant association with the outcome index once socioeconomic controls are added to the regression.

9 Specifically, this takes the form $y_{i}=\alpha+\sum_{j=20}^{44}\left(I_{j i} \delta_{j}\right)+x_{i}^{\prime} \gamma+\varepsilon_{i}$ where $I_{j}$ is an indicator variable for the mother's age (ranging from 20 to 44), $x_{i}^{\prime}$ is a vector of other SES variables (indicator variables for speaking English at home, Indigenous status, having both parents present, presence of a sibling in the home, whether that sibling is younger, four indicator variables for mother's education, four indicator variables for father's education, separate indicator variables for each state and territory, an indicator for living in a metropolitan area, an indicator for living in a remote area, and the ABS SEIFA advantage/disadvantage index of the socioeconomic status of the neighbourhood), $\alpha, \delta$, and $\gamma$ are parameters, and $\varepsilon_{i}$ is the error term in the linear model. 


\section{<Figure 5>}

\section{Conclusion}

In this paper, we ask two questions: How is maternal age related to child achievement? And is this relationship robust to holding constant family background? We find that children of older mothers do indeed perform better. In a simple specification, controlling only for a child's age and sex, maternal age is positively correlated with a child's learning, social and overall indices. The marginal effect of mother's age is stronger for younger mothers, but we find some evidence of better outcomes for children born to women in their thirties compared to children born to women in their twenties.

However, when we control for family income and a basic set of socioeconomic controls, the relationship between maternal age and child outcomes becomes statistically insignificant for the overall and learning index, and for the probability of being below the lower cut-off for the overall, learning or social index. This suggests that for these outcomes, maternal age at birth is not causing children to perform worse. For most child outcomes, maternal age is not the culprit for low cognitive performance, but merely a marker of other forms of disadvantage.

For government policy, the distinction between a marker and a cause has important implications. Since children with younger mothers generally have lower scores, it 
may sometimes be efficient to target additional government assistance towards the children of younger mothers. However, policymakers should be cautious about spending additional resources on programs that encourage young women to delay childbirth, since it is unlikely that maternal age has a causal impact on children's cognitive performance.

For the social outcome index, the relationship between maternal age and child outcomes is robust to adding socioeconomic controls. This raises two possibilities: first, it might be the case that our controls are not fully capturing important differences in family background that are correlated with both maternal age and child outcomes. Or second, it might be that maternal age affects children's social development, but not their cognitive development. Since most of the existing literature has used test scores (a measure of cognitive development) as the outcome variable, this would not necessarily be inconsistent with the existing literature. 


\section{References}

Australian Bureau of Statistics 2005, Births, Australia, Cat. No. 3301.0, ABS, Canberra.

Baldwin, W. and Cain, V. S. 1980, 'The children of teenage Parents', Family Planning Perspectives, vol. 12, pp. 34-43.

Barratt, M. S. 1991, 'School-age offspring of adolescent mothers: environments and outcomes', Family Relations, vol. 40, pp. 442-447.

Bradbury, B. 2006, 'The impact of young motherhood on Education, Employment and Marriage', Social Policy Research Centre Discussion Paper no. 148, University of New South Wales, Sydney.

Card, J. J. 1981, 'Long-term consequences for children of teenage parents', Demography, vol. 18, pp. 137-156.

Dubow, E. F. and Luster, T. 1990, 'Adjustment of Children Born to Teenage Mothers: The Contribution of Risk and Protective Factors', Journal of Marriage and the Family, vol. 52, pp. 393-404.

Fergusson, D. M. and Lynskey, M. T. 1993, 'Maternal age and cognitive and behavioural outcomes in middle childhood', Paediatric and perinatal epidemiology, vol. 7, pp. 77-91.

Fergusson, D. M. and Woodward, L. J. 1999, 'Maternal Age and educational and Psychosocial Outcomes in Early Adulthood', Journal of Child Psychology and Psychiatry, vol. 43, pp. 479-489.

Furstenberg, F. F. Jr., Brook-Gunn, J. and Morgan, P. 1987, 'Adolescent Mothers and Their Children in Later Life', Family Planning Perspectives, vol. 19, pp. 142-151.

Geronimus, A. and Korenman, S. 1992, 'The Socioeconomic Consequences of Teen Childbearing Reconsidered', Quarterly Journal of Economics, vol. 107, pp. 1187-1214.

Geronimus, A., Korenman, S. and Hillemeier, M. 1994, 'Does young maternal age adversely affect child development? Evidence from cousin comparisons in the United States', Population and Development Review, vol. 20, pp. 585-609.

Hollander, D. 2001, 'Young mother's disadvantage, not their age itself, accounts for their children's education problems', Family Planning Perspectives, vol. 33, pp. 
Levine, J. A. 2001, 'Academic and Behavioral Outcomes among the Children of Young Mothers', Journal of Marriage and Family, vol. 63, pp. 355-369.

Moore, K. A. and Snyder, N. O. 1991, 'Cognitive attainment among firstborn children of adolescent mothers', American Sociological Review, vol. 56, pp. 612-624.

Moore, K. A., Morrison, D. R. and Greene, A. D. 1997, 'Effect on the children born to adolescent mothers', in Kids having kids: Economic cost and social consequences of teen pregnancy, eds R. A. Maynard, Urban Institute Press, Washington, DC.

Saha, S., Barnett, A. G., Foldi, C., Burne, T. H., Eyles, D. W., Buka, S. L. and McGrath, J. J. 2009, 'Advanced Paternal Age Is Associated with Impaired Neurocognitive Outcomes during Infancy and Childhood', PLoS Medicine, vol. 6, no. 3, e1000040.

Sanson, A., Misson, S., Wake, M., Zubrick, S. R., Silburn, S., Rothman, S. and Dickenson, J. 2005, Summarising Children's Wellbeing: The LSAC Outcome Index LSAC Technical Paper \#2, Australian Institute of Family Studies, Melbourne.

Turley, R. N. L. 2003, 'Are Children of Young Mothers Disadvantaged Because of Their Mother's Age or Family Background?', Child Development, vol. 74, pp. 465-474. 


\section{Appendix 1: Summary of Variables Included in the \\ Outcome Indices for 4-5 Year-Olds \\ (Extracted from Sanson et al., 2005, Appendix B)}

\section{Learning Index}

Comprised from language, literacy, numeracy and approach to learning.

(a) Language

PPVT: A standardised Rasch-modelled score based on interviewer administration of an abbreviated form of the Peabody Picture Vocabulary Test (PPVT-III Form IIA, 1997), a measure of receptive language.

\section{(b) Literacy}

Parent rating of reading skills: parent rating on 3 yes/no items assessing whether a child has obtained reading skills at different levels of complexity, summed to give scores from 0 (good) to 3 (poor).

Teacher rating of reading skills: teacher yes/no ratings on 5 items; $0=$ poor skills, 5 = strong skills; available for 64 per cent of the sample. Items assess the level of complexity a child is capable of reading as well as the child's interest in reading.

Teacher rating of writing skills: teacher yes/no ratings on 6 items; $0=$ poor skills, $6=$ strong skills; available for 65 per cent of the sample. Items assess the level of complexity of the child's writing skills as well as the child's interest in writing.

\section{(c) Numeracy}

Teacher rating of numeracy skills: teacher yes/no ratings on 5 items; $0=$ poor skills, 5 = strong skills; available on about 64 per cent of the sample. Items assess the child's ability to perform numeric tasks such as counting, classifying, and simple addition, along with the ability to recognise numbers.

\section{(d) Approach to learning}

Who Am I? (WAI): Standardised score based on interviewer administration of the 'Who Am I?'(ACER, 1999), an Australian measure which assesses a child's ability to perform a range of tasks such as reading, writing, copying, and symbol recognition, as a measure of school readiness.

\section{Social/Emotional Index}

Comprised from social competence, internalising and externalising.

\section{(a) Social competence}

SDQ Prosocial: mean of 5 parent-rated items in the Prosocial sub-scale of the Strengths and Difficulties Questionnaire (SDQ, Goodman, 1999), assessing the child's propensity to behave in a way that is considerate and helpful to others, with items scored from 1 (not true) to 3 (certainly true); adequate reliability (alpha = 
$.66)$.

SDQ Peer problems: mean of 5 parent-rated items in the Peer sub-scale of the SDQ, assessing problems in the child's ability to form positive relationships with other children, with items scored from 1 (not true) to 3 (certainly true); fair reliability (alpha $=.50)$.

\section{(b) Internalising}

SDQ Emotional symptoms: mean of 5 parent-rated items in the Emotional Symptoms sub-scale of the SDQ, assessing a child's frequency of display of negative emotional states (for example nervousness, worry), with items scored from 1 (not true) to 3 (certainly true); fair reliability (alpha $=.58$ ).

\section{(c) Externalising}

SDQ Hyperactivity: mean of 5 parent-rated items in the Hyperactivity sub-scale of the SDQ, assessing a child's fidgetiness, concentration span and impulsiveness, with items scored from 1 (not true) to 3 (certainly true); good reliability (alpha = .74).

SDQ Conduct: mean of 5 parent-rated items in the Conduct sub-scale of the SDQ, assessing a child's tendency to display problem behaviours when interacting with others, with items scored from 1 (not true) to 3 (certainly true); good reliability (alpha $=.69)$.

\section{Overall Index}

Comprised from the learning index, social/emotional index, and the physical index, which is based on:

\section{(a) Health}

Overall health rating: single parent-rated item of child's health, from 1 (excellent) to 5 (poor).

Special health care needs: single derived yes/no item based on 6 component items indicating whether a child needed medication or more health care than the average child due to a condition that has lasted or was expected to last 12 months or more. Body-Mass Index (BMI): calculated from directly assessed variables of child's height and weight.

\section{(b) Motor}

PEDS QL Physical health subscale summary: 8-item parent-reported Physical sub-scale from PEDS QL (Varni, 1999), largely assessing motor coordination, but also containing 2 items about more general health, scaled to range from 0 (poor) to 100 (good). 
Appendix 2: Comparison Between Sub-Sample and Full Sample

\begin{tabular}{|c|c|c|c|}
\hline \multicolumn{4}{|c|}{ Table A1: Comparison Between Sub-Sample and Full Sample } \\
\hline Variable & $\begin{array}{c}\text { Mean of } \\
\text { sub-sample }\end{array}$ & $\begin{array}{c}\text { Mean of } \\
\text { full sample }\end{array}$ & $\begin{array}{c}\text { Non- } \\
\text { missing } \\
\text { obs. in full } \\
\text { sample }\end{array}$ \\
\hline Mother's age at time of child's birth & 30.279 & 30.470 & 4944 \\
\hline Dummy for child's Indigenous status & 0.034 & 0.038 & 4981 \\
\hline Dummy for male child & 0.513 & 0.509 & 4983 \\
\hline Child's age & 4.171 & 4.174 & 4983 \\
\hline Dummy for child speaking English & 0.897 & 0.889 & 4983 \\
\hline Birth weight $(\mathrm{g})$ & 3399.8 & 3399.396 & 4897 \\
\hline Dummy, 1 if sibling in household & 0.881 & 0.885 & 4983 \\
\hline Dummy, 1 if younger sibling in household & 0.475 & 0.468 & 4983 \\
\hline Dummy, 1 if both parents in the household & 0.851 & 0.860 & 4983 \\
\hline $\begin{array}{l}\text { Dummy, } 1 \text { if mother received higher } \\
\text { education }\end{array}$ & 0.280 & 0.283 & 4979 \\
\hline Dummy, 1 if mother received a certificate & 0.268 & 0.261 & 4979 \\
\hline Dummy, 1 if mother received a diploma & 0.088 & 0.089 & 4979 \\
\hline Dummy, 1 if mother did not finish year 12 & 0.216 & 0.211 & 4979 \\
\hline $\begin{array}{l}\text { Dummy, } 1 \text { if father received higher } \\
\text { education }\end{array}$ & 0.238 & 0.251 & 4967 \\
\hline Dummy, 1 if father received a certificate & 0.326 & 0.328 & 4968 \\
\hline Dummy, 1 if father received a diploma & 0.069 & 0.070 & 4967 \\
\hline Dummy, 1 if father did not finish year 12 & 0.135 & 0.133 & 4968 \\
\hline
\end{tabular}

Note: Table shows selected socioeconomic variables only. Sub-sample contains 3,996 observations. 
Figure 1: Median Age of Mother, 1921-2004

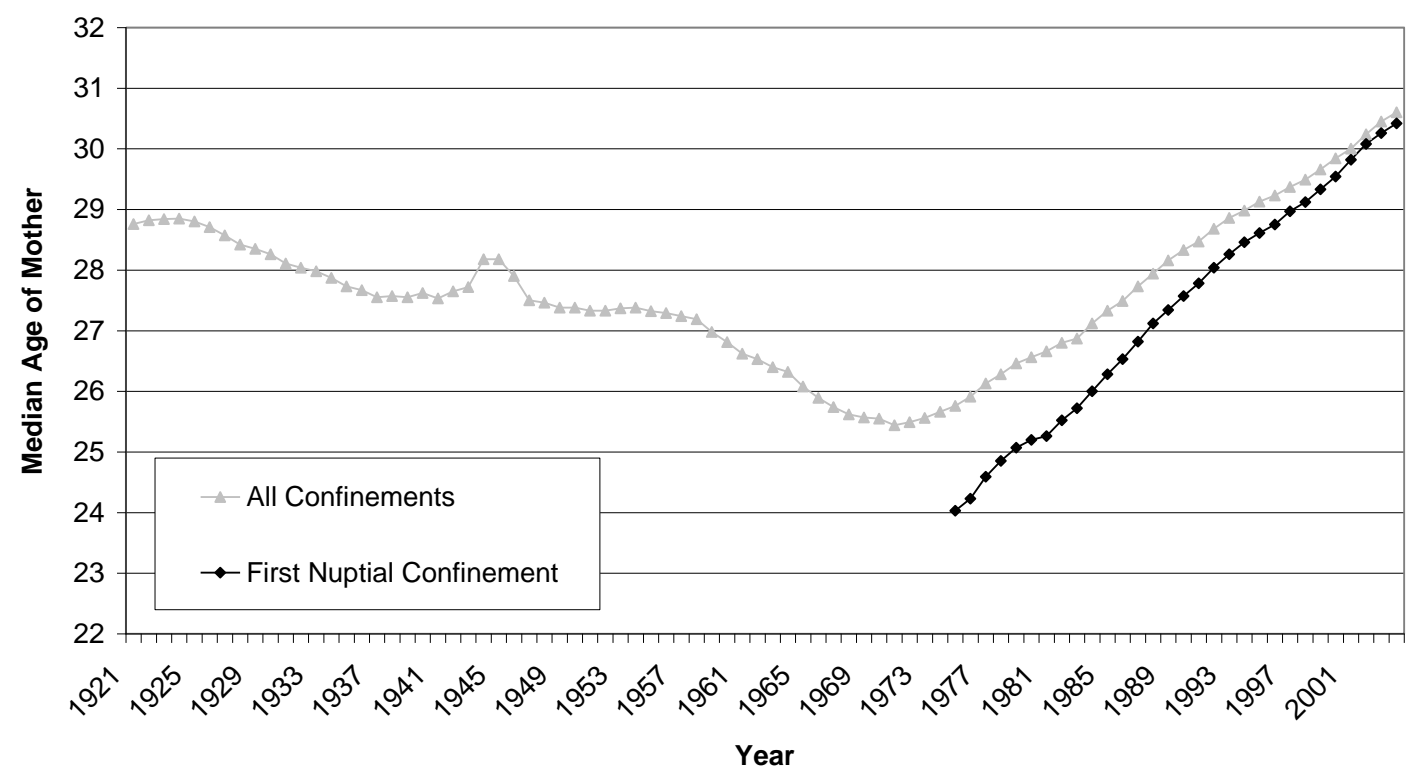

Figure 2: Age-Specific Fertility Rates, 1924-2004

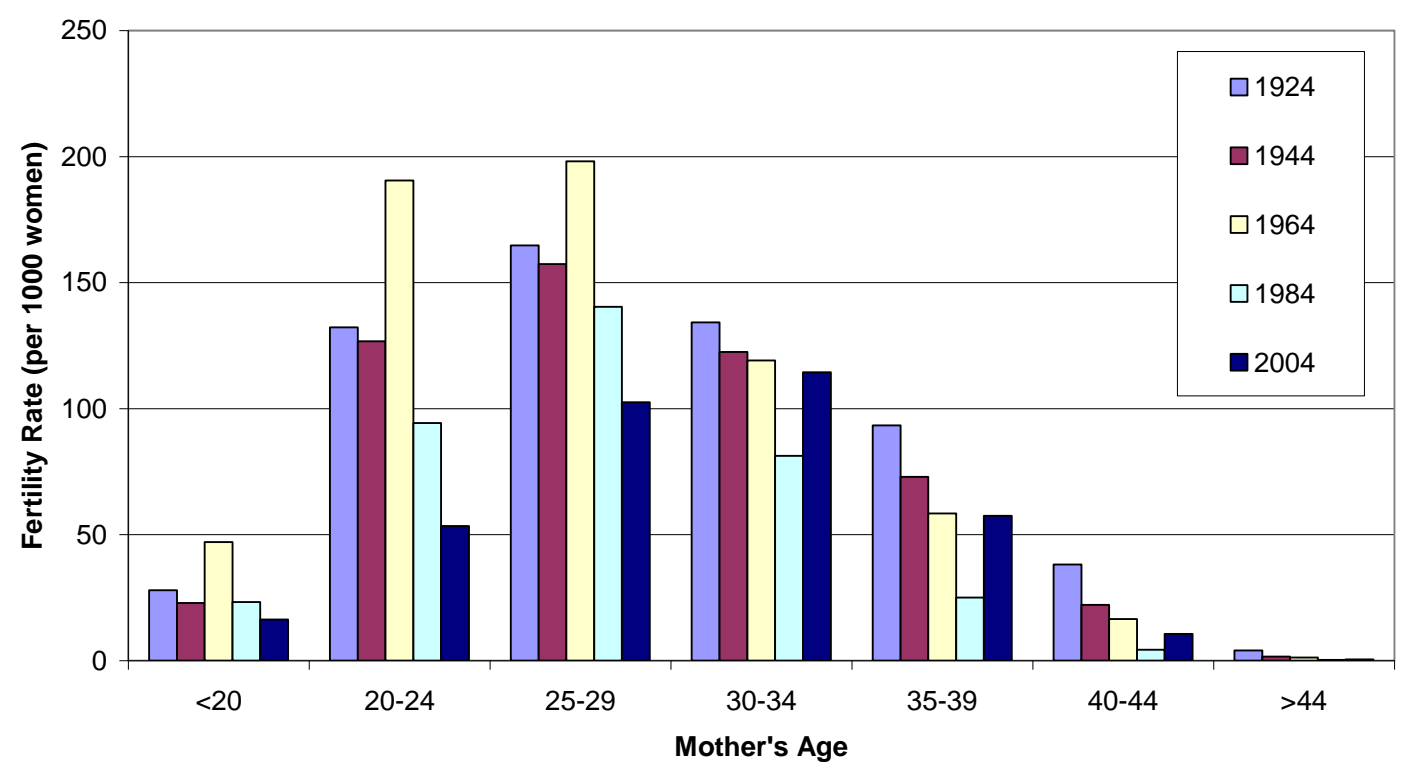


Figure 3: Distribution of Mother's Age at Birth

in LSAC Sample and the Australian Population

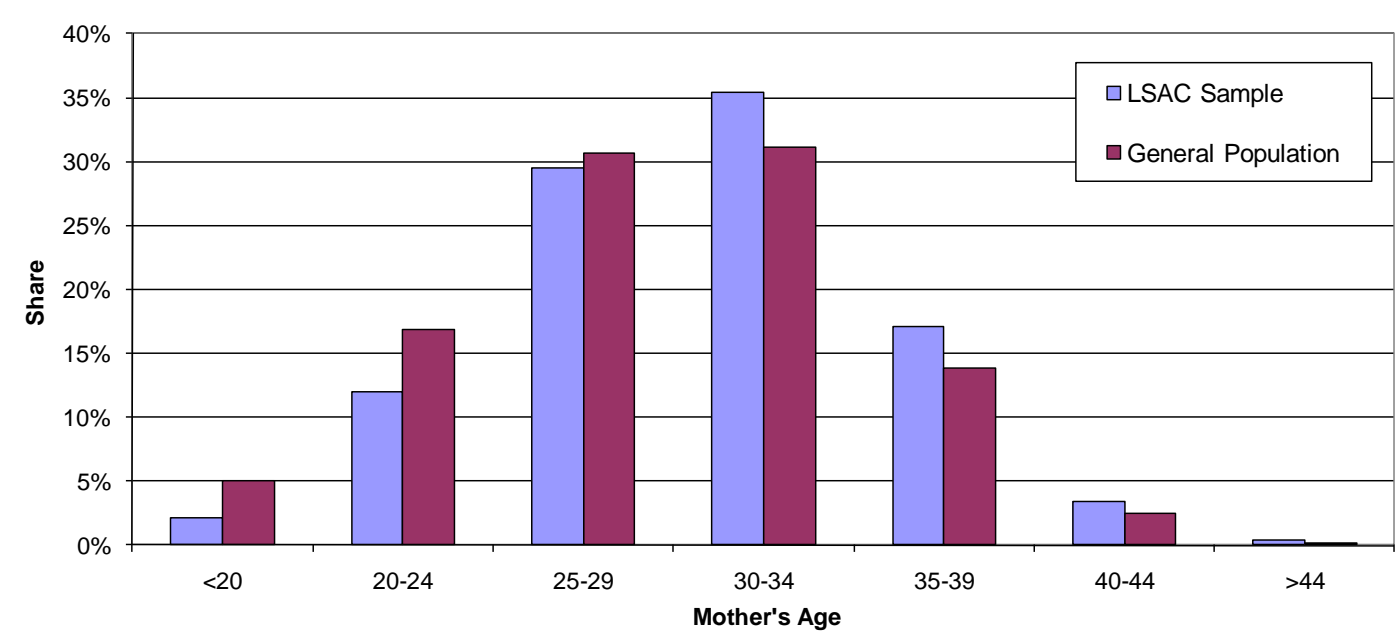

Note: LSAC sample comprises 3,996 respondents. General population data is derived from ABS Births statistics for 2000.

Figure 4: Non-Parametric Relationship Between Mother's Age and Child's Overall Outcome Index

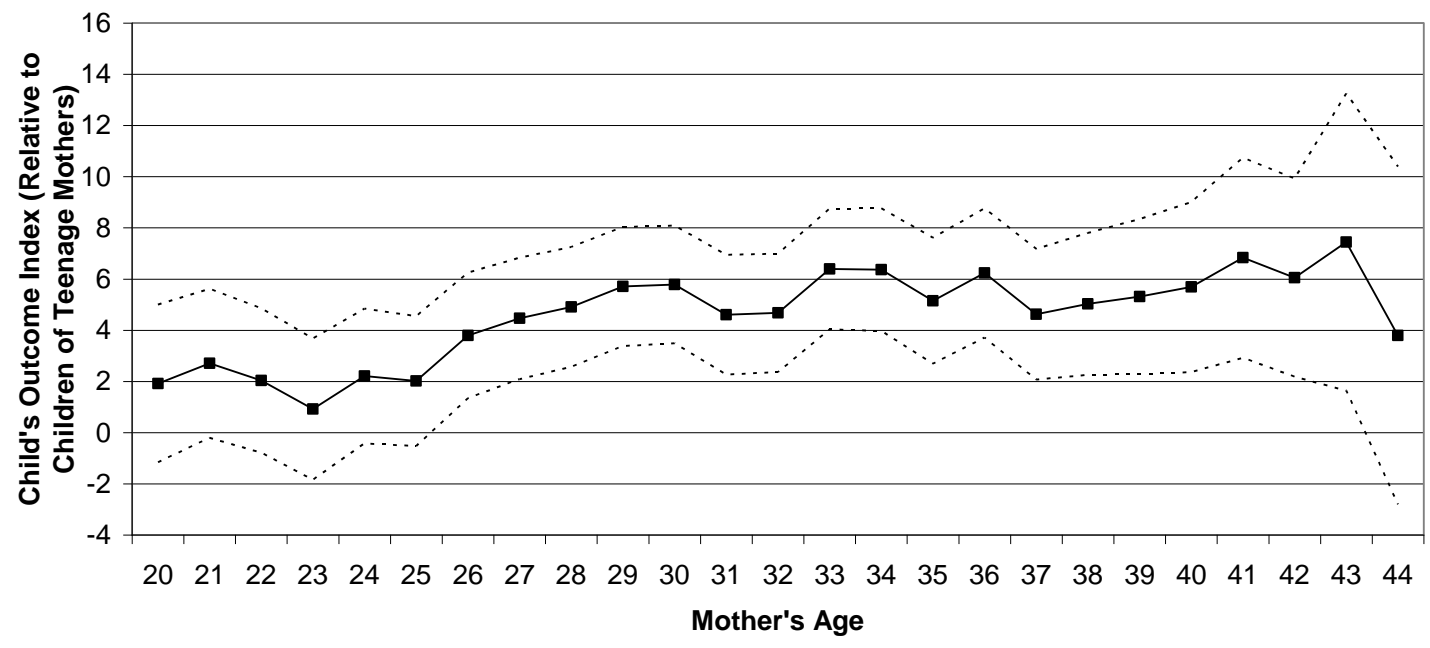

Note: Results are from an OLS regression controlling for child's sex and age at time of testing. Excluded group is mothers aged less than 20. 
Figure 5: Non-Parametric Relationship Between Mother's Age and Child's Overall Outcome Index (Controlling for SES)

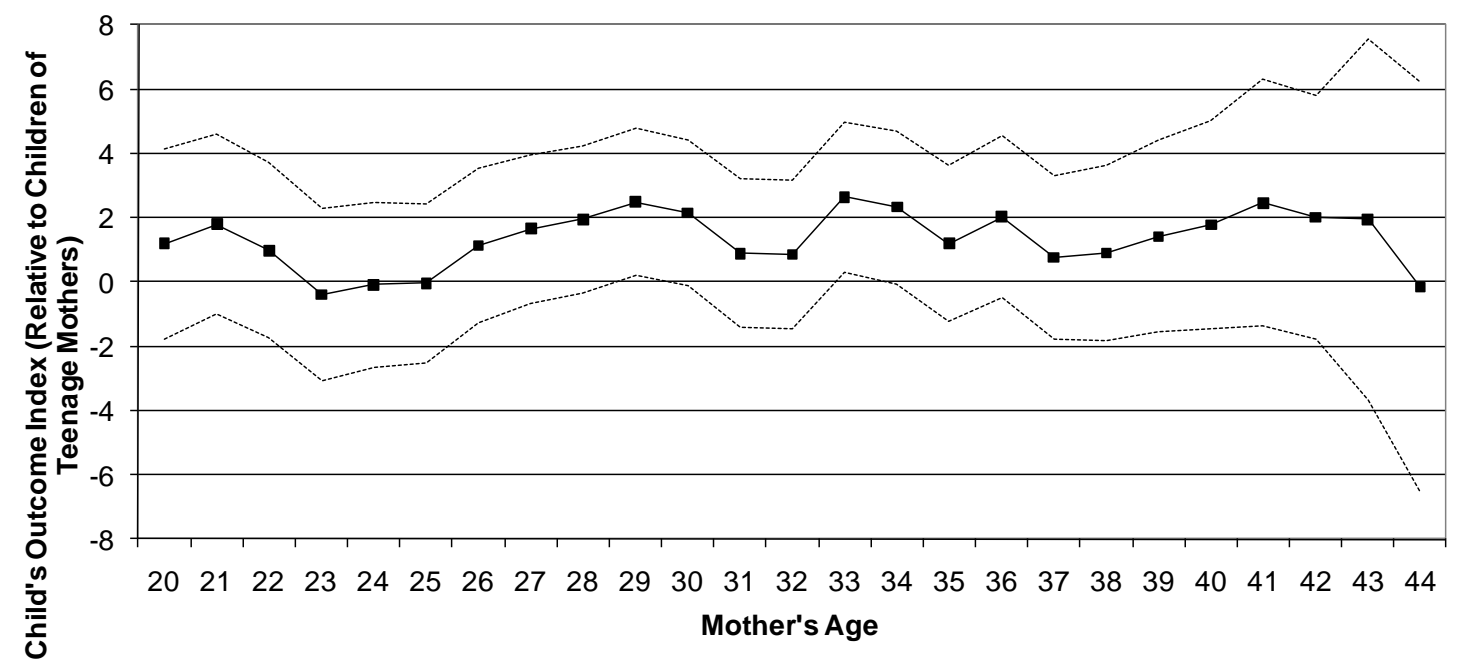

Note: Results are from an OLS regression controlling for child's sex, child's age at time of testing, and SES controls (see text for details). Excluded group is mothers aged less than 20. 


\begin{tabular}{lrr}
\hline Table 1: Summary statistics & & \\
\hline Variable & 100.393 & Std. dev. \\
Overall development index (continuous) & 100.349 & 9.85 \\
Index for social/emotional domain (continuous) & 100.328 & 9.92 \\
Index for learning domain (continuous) & 0.140 & \\
Dummy, below lower cut-off in learning domain & 0.139 & \\
Dummy, below lower cut-off in social domain & 0.321 & \\
Dummy, below lower cut-off in at least one domain & 30.279 & 5.31 \\
Mother's age at time of child's birth & 0.513 & \\
Dummy for male child & 4.171 & 0.38 \\
Child's age at time of testing & 1309.888 & 885.43 \\
Family weekly income from all sources, before tax $(\$)$ & 3996 & \\
Number of observations & & \\
\hline
\end{tabular}

Table 2: Maternal Age and the Overall Index

\begin{tabular}{lcccc}
\hline & {$[1]$} & {$[2]$} & {$[3]$} & {$[4]$} \\
Mother's Age & $1.282^{* * *}$ & $0.661 * * *$ & 0.306 & 0.346 \\
& {$[0.252]$} & {$[0.253]$} & {$[0.253]$} & {$[0.254]$} \\
Mother's Age ${ }^{2}$ & $-0.015^{* * *}$ & $-0.008^{* *}$ & -0.004 & -0.004 \\
& {$[0.004]$} & {$[0.004]$} & {$[0.004]$} & {$[0.004]$} \\
Male & $-3.475 * * *$ & $-3.491^{* * *}$ & $-3.657 * * *$ & $-3.519 * * *$ \\
& {$[0.304]$} & {$[0.298]$} & {$[0.292]$} & {$[0.292]$} \\
Child's Age & $0.960 * *$ & $1.031^{* * *}$ & $1.222^{* * *}$ & $1.181^{* * *}$ \\
& {$[0.403]$} & {$[0.396]$} & {$[0.387]$} & {$[0.389]$} \\
Log family income & & $3.002^{* * *}$ & $1.131^{* * *}$ & $1.135^{* * *}$ \\
& & {$[0.244]$} & {$[0.305]$} & {$[0.306]$} \\
SES Controls & No & No & Yes & Yes \\
Birth Weight Control & No & No & No & Yes \\
Observations & 3996 & 3996 & 3996 & 3996 \\
R-squared & 0.053 & 0.087 & 0.140 & 0.133 \\
\hline
\end{tabular}

Notes: Estimates are from an OLS model, with standard errors in brackets. *, ** and *** denote statistical significance at the 10 per cent, 5 per cent and 1 per cent levels, respectively. SES controls are indicator variables for speaking English at home, Indigenous status, having both parents present, presence of a sibling in the home, whether that sibling is younger, four indicator variables for mother's education, four indicator variables for father's education, separate indicator variables for each state and territory, an indicator for living in a metropolitan area, an indicator for living in a remote area, and the ABS SEIFA advantage/disadvantage index of the socioeconomic status of the neighbourhood. 


\begin{tabular}{|c|c|c|c|c|}
\hline \multicolumn{5}{|c|}{ Table 3: Maternal Age and the Learning Index } \\
\hline \multirow{3}{*}{ Mother's Age } & [1] & [2] & [3] & [4] \\
\hline & $1.028 * * *$ & 0.384 & 0.203 & 0.243 \\
\hline & {$[0.250]$} & [0.252] & {$[0.250]$} & [0.251] \\
\hline \multirow[t]{2}{*}{ Mother's Age ${ }^{2}$} & $-0.012 * * *$ & -0.004 & -0.002 & -0.003 \\
\hline & {$[0.004]$} & {$[0.004]$} & {$[0.004]$} & {$[0.004]$} \\
\hline \multirow[t]{2}{*}{ Male } & $-4.190 * * *$ & $-4.190 * * *$ & $-4.374 * * *$ & $-4.235 * * *$ \\
\hline & {$[0.301]$} & {$[0.296]$} & {$[0.288]$} & {$[0.288]$} \\
\hline \multirow[t]{2}{*}{ Child's Age } & $2.092 * * *$ & $2.191 * * *$ & $2.343 * * *$ & $2.302 * * *$ \\
\hline & {$[0.400]$} & {$[0.393]$} & {$[0.382]$} & {$[0.384]$} \\
\hline \multirow[t]{2}{*}{ Log family income } & & $2.608 * * *$ & $0.650 * *$ & $0.655^{* *}$ \\
\hline & & {$[0.243]$} & {$[0.301]$} & {$[0.303]$} \\
\hline SES Controls & No & No & Yes & Yes \\
\hline Birth Weight Control & No & No & No & Yes \\
\hline Observations & 3996 & 3996 & 3996 & 3996 \\
\hline R-squared & 0.064 & 0.095 & 0.157 & 0.149 \\
\hline \multicolumn{5}{|l|}{ Notes: As for Table 2.} \\
\hline \multicolumn{5}{|c|}{ Table 4: Maternal Age and the Social Index } \\
\hline \multirow{3}{*}{ Mother's Age } & {$[1]$} & [2] & [3] & [4] \\
\hline & $1.601 * * *$ & $1.032 * * *$ & $0.667 * *$ & $0.687 * * *$ \\
\hline & {$[0.256]$} & {$[0.257]$} & {$[0.259]$} & {$[0.259]$} \\
\hline \multirow[t]{2}{*}{ Mother's Age ${ }^{2}$} & $-0.019 * * *$ & $-0.012 * * *$ & $-0.009 * *$ & $-0.009 * *$ \\
\hline & {$[0.004]$} & [0.004] & [0.004] & [0.004] \\
\hline \multirow[t]{2}{*}{ Male } & $-2.397 * * *$ & $-2.412 * * *$ & $-2.508 * * *$ & $-2.439 * * *$ \\
\hline & {$[0.308]$} & [0.303] & {$[0.298]$} & [0.298] \\
\hline \multirow[t]{2}{*}{ Child's Age } & -0.062 & 0.003 & 0.159 & 0.138 \\
\hline & [0.409] & {$[0.403]$} & {$[0.396]$} & {$[0.396]$} \\
\hline \multirow[t]{2}{*}{ Log family income } & & $2.753 * * *$ & $1.104 * * *$ & $1.106 * * *$ \\
\hline & & {$[0.248]$} & {$[0.312]$} & {$[0.312]$} \\
\hline SES Controls & No & No & Yes & Yes \\
\hline Birth Weight Control & No & No & No & Yes \\
\hline Observations & 3996 & 3996 & 3996 & 3996 \\
\hline R-squared & 0.041 & 0.069 & 0.114 & 0.112 \\
\hline
\end{tabular}




\begin{tabular}{lcccc}
\hline \multicolumn{4}{l}{ Table 5: Maternal Age and Being in the Problematic Area for Any Index } \\
\hline \multirow{2}{*}{ Mother's Age } & {$[1]$} & {$[2]$} & {$[3]$} & {$[4]$} \\
& $-0.040^{* * *}$ & -0.015 & -0.006 & -0.008 \\
Mother's Age ${ }^{2}$ & {$[0.012]$} & {$[0.013]$} & {$[0.013]$} & {$[0.013]$} \\
& $0.000^{* * *}$ & 0 & 0 & 0 \\
Male & {$[0.000]$} & {$[0.000]$} & {$[0.000]$} & {$[0.000]$} \\
& $0.113^{* * *}$ & $0.116^{* * *}$ & $0.125^{* * *}$ & $0.119^{* * *}$ \\
Child's Age & {$[0.015]$} & {$[0.015]$} & {$[0.015]$} & {$[0.015]$} \\
& -0.003 & -0.006 & -0.015 & -0.014 \\
Log family income & {$[0.020]$} & {$[0.020]$} & {$[0.020]$} & {$[0.020]$} \\
& & $-0.122^{* * *}$ & $-0.063 * * *$ & $-0.063^{* * *}$ \\
SES Controls & & {$[0.012]$} & {$[0.016]$} & {$[0.016]$} \\
Birth Weight Control & No & No & Yes & Yes \\
Observations & No & No & No & Yes \\
\hline
\end{tabular}

Notes: Dependent variable is an indicator for whether the child is in a problematic area for any of the three indices (physical, social, or learning). Coefficients are marginal probabilities from a probit model. Standard errors in brackets. $*, * *$ and $* * *$ denote statistical significance at the 10 per cent, 5 per cent and 1 per cent levels, respectively. SES controls are indicator variables for speaking English at home, Indigenous status, having both parents present, presence of a sibling in the home, whether that sibling is younger, four indicator variables for mother's education, four indicator variables for father's education, separate indicator variables for each state and territory, an indicator for living in a metropolitan area, an indicator for living in a remote area, and the ABS SEIFA advantage/disadvantage index of the socioeconomic status of the neighbourhood. 
Table 6: Maternal Age and Being in the Problematic Area for the Learning Index

\begin{tabular}{lcccc}
\hline & {$[1]$} & {$[2]$} & {$[3]$} & {$[4]$} \\
Mother's Age & $-0.025^{* * *}$ & -0.012 & -0.003 & -0.004 \\
& {$[0.009]$} & {$[0.009]$} & {$[0.009]$} & {$[0.009]$} \\
Mother's Age ${ }^{2}$ & $0.000^{* *}$ & 0 & 0 & 0 \\
Male & {$[0.000]$} & {$[0.000]$} & {$[0.000]$} & {$[0.000]$} \\
& $0.056^{* * *}$ & $0.057 * * *$ & $0.059^{* * *}$ & $0.057^{* * *}$ \\
Child's Age & {$[0.011]$} & {$[0.011]$} & {$[0.010]$} & {$[0.010]$} \\
& $0.030^{* *}$ & $0.028^{* *}$ & $0.024^{*}$ & $0.025^{*}$ \\
Log family income & {$[0.014]$} & {$[0.014]$} & {$[0.013]$} & {$[0.013]$} \\
& & $-0.063^{* * *}$ & $-0.019 *$ & $-0.019^{*}$ \\
SES Controls & & {$[0.009]$} & {$[0.011]$} & {$[0.011]$} \\
Birth Weight Control & No & No & Yes & Yes \\
Observations & No & No & No & Yes \\
\hline
\end{tabular}

Notes: Coefficients are marginal probabilities from a probit model. Standard errors in brackets. *, ** and $* * *$ denote statistical significance at the 10 per cent, 5 per cent and 1 per cent levels, respectively. SES controls are indicator variables for speaking English at home, Indigenous status, having both parents present, presence of a sibling in the home, whether that sibling is younger, four indicator variables for mother's education, four indicator variables for father's education, separate indicator variables for each state and territory, an indicator for living in a metropolitan area, an indicator for living in a remote area, and the ABS SEIFA advantage/disadvantage index of the socioeconomic status of the neighbourhood.

Table 7: Maternal Age and Being in the Problematic Area for the Social Index

\begin{tabular}{lcccc}
\hline & {$[1]$} & {$[2]$} & {$[3]$} & {$[4]$} \\
Mother's Age & $-0.026^{* * *}$ & -0.011 & -0.008 & -0.01 \\
& {$[0.008]$} & {$[0.008]$} & {$[0.008]$} & {$[0.008]$} \\
Mother's Age ${ }^{2}$ & $0.000^{* * *}$ & 0 & 0 & 0 \\
Male & {$[0.000]$} & {$[0.000]$} & {$[0.000]$} & {$[0.000]$} \\
& $0.088^{* * *}$ & $0.089^{* * *}$ & $0.092^{* * *}$ & $0.088^{* * *}$ \\
Child's Age & {$[0.011]$} & {$[0.011]$} & {$[0.010]$} & {$[0.010]$} \\
& $-0.039 * * *$ & $-0.042^{* * *}$ & $-0.047 * * *$ & $-0.045^{* * *}$ \\
Log family income & {$[0.015]$} & {$[0.015]$} & {$[0.014]$} & {$[0.014]$} \\
& & $-0.073^{* * *}$ & $-0.036^{* * *}$ & $-0.036^{* * *}$ \\
SES Controls & & {$[0.008]$} & {$[0.011]$} & {$[0.011]$} \\
Birth Weight Control & No & No & Yes & Yes \\
Observations & No & No & No & Yes \\
\hline
\end{tabular}

Notes: As for Table 6. 